\title{
Fourier transform infrared and fluorescence spectroscopy for analysis of vegetable oils
}

\author{
S. Nigri and R. Oumeddour \\ Laboratoire d'Analyses Industrielles et Génie des Matériaux, Université 8 mai 1945 Guelma, BP. 401, \\ Guelma 24000, Algeria
}

\begin{abstract}
Fourier transform infrared (FTIR) and fluorescence spectroscopy, combined with chemometric approaches have been developed to analysis of extra virgin olive oil adulterated with pomace olive oil. The measurements were made on pure vegetable oils: extra virgin oil, pomace olive oil and that adulterated with varying concentration of pomace olive oil. Today, the application of FTIR spectroscopy has increased in food studied, and particularly has become a powerful analytical tool in the study of edible oils and fats. The spectral regions where the variations were observed chosen for developing models and cross validation was used. The synchronous fluorescence spectrometry takes advantage of the hardware capability to vary both the excitation and emission wavelengths during the analysis with constant wavelength difference is maintained between the two. The region between 300 and $400 \mathrm{~nm}$ is attributed to the tocopherols and phenols, the derivatives of vitamin $\mathrm{E}$ are associated with the region $400-600 \mathrm{~nm}$ and the bands in the region of $600-700 \mathrm{~nm}$ are attributed to the chlorophyll and peophytin pigments. The results presented in this study suggest that FTIR and fluorescence may be a useful tool for analysis and detecting adulteration of extra virgin olive oil with pomace oil.
\end{abstract}

\section{INTRODUCTION}

Adulteration of edible oils has been a chronic illness in food adulteration for many years [1]. It not only causes serious health problems [2], but also undermines the integrity and orderly economy. The adulteration involved the replacement of high priced ingredients with cheaper substitutes. Olive oil is frequently subjected to be adulteration with other edible oils of lower commercial value [3], mainly sunflower, corn, palm, hazelnut, soya, soybean, pomace and canola oils due to their close resemblance to virgin olive oil composition $[4,5]$. To discriminate among different oils as well as to detect adulteration, many analytical techniques can be used [7]. Thermal techniques such as thermogravimetric analysis (TGA) [6] and differential scanning calorimetry (DSC) are also used [7]. Chromatographic methods: gas and liquid chromatography (GC and HPLC) [8] are employed for the control of authenticity of virgin olive oil. However, these techniques are time consuming, expensive, required skilled operator and produce hazardous chemical waste [5]. Therefore, spectroscopic techniques require no or limited sample preparation, including fluorescence [4], NMR [9], FTIR [1], FT-Raman [10] and MS [11] combined with chemometrics analysis have usually been used. Today, the application of Fourier transform infrared spectroscopy (FTIR) has become a powerful analytical tool in the study of edible oils and fats [11]. FTIR as a quantitative tool, present an alternative solution, when it is coupled with chemometrics methods. Several studies have reported the application of chemometrics techniques applied to FTIR spectral data for quantitative analysis of certain oils. The presence of hazelnut oil [13], sunflower and corn oils [14], sunflower, corn, soybean and hazelnut oils [15], sunflower, soybean, sesame, and corn oils [16], palm oil [17] and rice bran oil [18] has been analyzed using FTIR spectroscopy combined with chemometrics techniques.
Different approaches based on florescence spectroscopy have been implemented for the characterization of edible oils [19]. Among the benefits of fluorescence spectroscopy is it high sensitivity to a wide array of potential analytes, and in general, avoidance of consumable reagents and extensive sample pretreatment [20]. The differences between the fluorescence spectra of olive oil and other edible oils [21] and between different categories of olive have also been used to detect adulterations, as the presence of hazelnut oil in virgin olive oil [22] and even to determine the thermal deterioration in virgin olive oil [19].

Conventional fluorescence techniques, relying on measurements of single emission or excitation spectra, are often insufficient in the analysis of complex systems [21]. In such case, synchronous scanning fluorescence spectrometry takes advantage of the hardware capability to vary both the excitation and emission wavelengths during the analysis [23]. In this method, excitation and emission monochromators are scanned simultaneously, synchronized so that a constant wavelength difference is a maintained between the two.

The objective of this research we developed FTIR and synchronous scanning fluorescence spectrometry combined with multivariate calibration, for quantitative analyses of extra virgin olive oil EVOO adulterated with pomace olive oil POO.

\section{MATERIALS AND METHODS}

\subsection{Sample preparation}

Extra virgin olive oil and pomace olive oil were purchased from the local market in Guelma, Algeria. 


\subsection{FTIR spectra}

FTIR spectra were obtained using a Perkin-Elmer Spectrum (spectrum one) spectrophotometer with a resolution of $4 \mathrm{~cm}^{-1}$ at 10 scans. A small quantity of the oil samples was directly deposited between two wellpolished $\mathrm{KBr}$ disks, creating a thin film. Duplicated spectra were recorded for all the oil samples and binary mixtures. Spectra were scanned in the absorbance mode from 4000 to $450 \mathrm{~cm}^{-1}$. In order to reduce the variability associated with total amount of oil sample used, and to minimize other sources of variance affecting the intensity of peaks, spectra were normalized.

\subsection{Fluorescence spectra}

All spectrofluorimetric measurements were carried out by a Shimadzu RF-5301PC spectrometer. A xenon lamp source was used for excitation. The excitation and emission slit widths were $3 \mathrm{~nm}$. The acquisition interval and the integration time were maintained at $2 \mathrm{~nm}$ and $0.02 \mathrm{~s}$ respectively. The oil samples were diluted in $\mathrm{n}$-hexane $(1 \% \mathrm{~V} / \mathrm{V})$ in a $10 \mathrm{~mm}$ fused quartz cell. The low concentration of the samples was chosen to avoid spectral distortions, which may occur in more concentrated solutions [23]. The synchronous fluorescence spectra were collected by simultaneously scanning the excitation the emission monochromators in the $220-900 \mathrm{~nm}$ range, with a constant wavelength difference $\Delta \lambda=30,40$ and $50 \mathrm{~nm}$ between them.

Minitab 16 was used for data processing and analysis.

\section{RESULTS AND DISCUSSION}

The oils have different substitution patterns, also differing in the chain length of their acyl moieties, as well as in their unsaturation degree and position; these differences are reflected in the FTIR spectra [24]. The importance of IR spectroscopy in the identification of molecular structures originates from the much information content obtained and the possibility to assign certain absorption bands related to its functional groups $[17,25]$.

Figure 1 exhibits FTIR spectra of EVVO and POO at $4000-450 \mathrm{~cm}^{-1}$. The two spectra were similar to naked eye. This is due to the similar chemical composition of EVOO and POO. The presence of small amounts of adulterant oil in EVOO is evidenced by small variations in the values of peak intensity of specific bands in the spectra.

The analysis of the variations in FTIR spectra is not very easy, because these changes are very weak. PLS is one of the most used tools for the study of the adulteration of extra virgin olive oil with pomace olive oil. PLS was able to find an acceptable correlation (see Figure 2). The optimum number of PLS factors was determined using cross validation. Two latent variables were used to build the model. The performance of the model was evaluated by the coefficient of determination $\mathrm{R}^{2}\left(\mathrm{R}^{2}=0.98\right)$.

As indicate in Figure 2, the PLS method has good predictive ability for the determination at frequencies of $3500-2660,1750-720 \mathrm{~cm}^{-1}$.

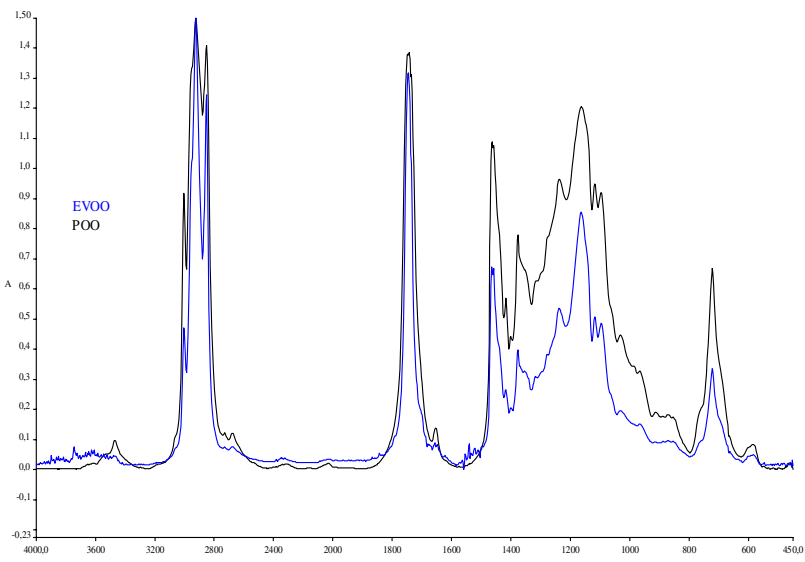

Figure 1. FTIR spectra of EVOO and POO at frequency of $4000-450 \mathrm{~cm}^{-1}$.

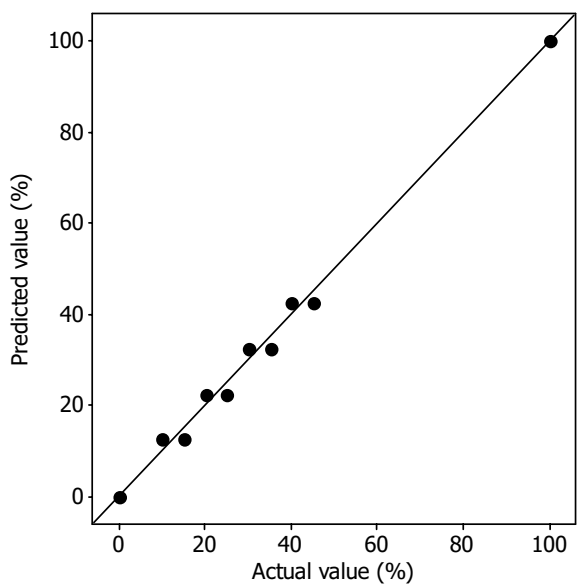

Figure 2. Correlation plot of the predicted versus the actual value (\%) of $\mathrm{POO}$ in $\mathrm{EVOO}$

The chemometric analysis demonstrate that the fingerprint regions can be observed at frequency of $3473 \mathrm{~cm}^{-1}$ caused by $-\mathrm{C}=\mathrm{O}$ (ester) overtone vibration, at $2679 \mathrm{~cm}^{-1}$ which attributed to carbonyl group (Fermi resonance) and at $1663 \mathrm{~cm}^{-1}$ caused by $\mathrm{C}=\mathrm{C}$ (cis) stretching vibration.

The relationship between actual value (\%) of POO and FTIR predicted value showed a good correlation with $\mathrm{R}^{2}=0.998$.

Synchronous fluorescence spectroscopy could beneficial for the analysis of multi-component samples such as olive oil without prior separation. The main fluorescent components identified in olive oils are tocopherol (vitamin E), chlorophyll and phenolic antioxydants [23]. Synchronous fluorescence spectra, SynFS of extra virgin olive oil and pomace olive oil acquired at $\Delta \lambda=30,40$ and $50 \mathrm{~nm}$ are shown in Figure 3 and Figure 4.

It is Cleary shown that the two classes of oil are differentiated in region of 300 to $400 \mathrm{~nm}$ attributed to the tocopherols and phenols and 600 to $700 \mathrm{~nm}$ attributed to the chlorophyll and peophytin pigments. 


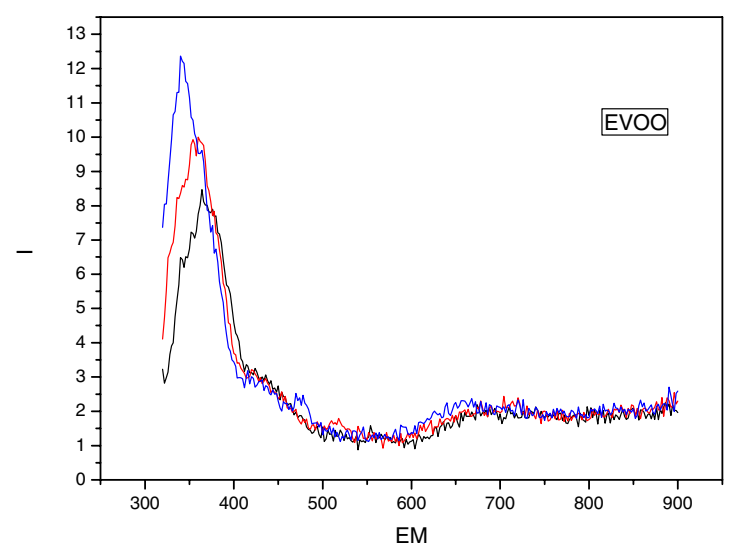

Figure 3. Synchronous fluorescence spectra of EVOO at $\Delta \lambda=$ 30,40 and $50 \mathrm{~nm}$.

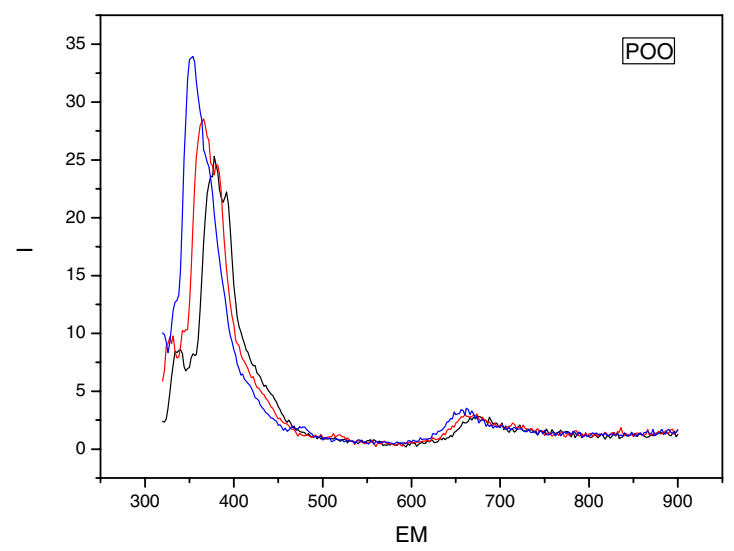

Figure 4. Synchronous fluorescence spectra of EVOO at $\Delta \lambda=$ 30,40 and $50 \mathrm{~nm}$.

\section{CONCLUSION}

FTIR combined with Synchronous fluorescence spectroscopy can be used to monitor the adulteration of extra virgin olive oil with much cheaper oil like pomace olive oil.

\section{References}

[1] Q. Zhang, C. Liu, Z. Sun, X. Hu, Q. Shen, J. Wu, Food Chem. 132, 1607 (2012).

[2] F. Guimet, J. Ferré, R. Boqué, Anal. Chim. Acta 544, 143 (2005).

[3] G. Flores, M. L. Ruiz del Castillo, Gracia, P. Blanch, M. Herraiz, Food Chem. 97, 336 (2007).
[4] K.I. Poulli, Anal. Bioanal. Chem. 386, 1571 (2009).

[5] S. M. Obeidat, M. S. Khanfar, W. M. Obeidat, Aust. J. Basic Appl Sci., 3, 2048 (2009).

[6] S. Vecchio, L. Cerretani, A. Bendini, E. Chiavaro, J. Agric. Food Chem. 57, 4793 (2009).

[7] J.S. Torrecilla, J. García, S. García, F. Rodríguez, J. Food Eng. 103, 211 (2011).

[8] G. Flores, M. L. Ruiz Del Castillo, M. Herraiz, G. P. Blanch, Food Chem. 97, 742 (2006).

[9] M. Jafari, M. Kadivar, J. Keramat, J. Am. Oil Chem. Soc. 86, 103 (2009).

[10] M. Q. Zou, X. F. Zhang, X. H. Qi, H.L. Ma, Y. Dong, C. W. Liu, X. Guo, H. Wang, J. Agri. Food Chem. 57, 6001 (2009).

[11] M.J. Lerma-García, J.M. Herrero-Martínez, G. Ramis-Ramos, E.F. Simó-Alfonso, food Chem. 107, 1307 (2008).

[12] M. D. Guillén, N. Cabo, J. Sci. Food Agri. 80, 2028 (2000).

[13] V. Baeten, J. Antonio, F. Pierna, P. Dardenne, M. Meurens, D.L. Garcia- Gonzalez, R. Aparicio-Ruiz, J. Agric. Food Chem. 53, 6201 (2005).

[14] D. Özdemir, B. Öztürk, J. Food Drug Anal. 15, 40 (2007).

[15] M. J. Lerma-García, G. Ramis-Ramos, J.M. HerreroMartínez, E.F. Simó-Alfonso, Food Chem. 118, 78 (2010).

[16] N. Vlachos, Y. Skopelitis, M. Psaroudaki, V. Konstantinidou, A. Chatzilazarou, E. Tegou, Anal. Chim. Acta 573-574, 459 (2006).

[17] A. Rohman, Y.B. Che Man, Food Res. Int. 43, 886 (2010).

[18] A. Rohman, Y. B. Che Man, Chemometr. Intell. Lab. 110, 129 (2012).

[19] N. Tena, R. Aparicio, D. L. García-González, Food Res. Int. 45, 103 (2012).

[20] P.B. Oldham, M.E. McCarroll, L.B. McGown, I.M. Warner, Anal. Chem. 72, 197R (2000).

[21] E. Sikorska, T. Górecki, I. V. Khmelinskii, M. Sikorski, J. Kozio, Food Chem. 89, 217 (2005).

[22] A. Sayago, M.T. Morales and R. Aparicio, European Food Research and Technology, 218, 480 (2004).

[23] E. Sikorska, I. V. Khmelinskii, M. Sikorski, F.Caponio, M. T. Bilancia, A. Pasqualone, T. Gomes, Int. J. Food Sci.Tech. 43, 52 (2008).

[24] R. M. Maggio, L. Cerretani, E. Chiavaro, T. S. Kaufman, A. Bendini, Food Control 21, 890 (2010).

[25] A. Bendini, L. Cerretani, F. Di Virgilio, P. Belloni, M. Bonoli-Carbognin, G. Lercker, J. Food Quality 30, 424 (2007). 